\title{
Study of the dispersion process of vehicular emissions at a specific site in Belo Horizonte using numerical simulation
}

\author{
V. Jacomino ${ }^{1}$, F. Tavares ${ }^{1}$, A. Barreto ${ }^{1}$ \& E. Dutra ${ }^{2}$ \\ ${ }^{I}$ Developing Center of Nuclear Technology, Brazil \\ ${ }^{2}$ Environmental Protection Agency of Minas Gerais State, Brazil
}

\begin{abstract}
In this study, the California Line Source for Queuing \& Hot Spot Calculations Refined (CAL3QHCR) model was used to assess the contribution of particulate matter (PM) from vehicular exhausts to the air quality of a specific site in downtown Belo Horizonte. Meteorological, traffic, signalization, and vehicular emissions data were collected and analyzed according to the CAL3QHCR model's requirements. Due to the absence of PM emission factors for the Belo Horizonte region, it was opted to use previously established factors for vehicles as measured in the São Paulo metropolitan area. Concentration results obtained through simulations were compared to $\mathrm{PM}_{10}$ and $\mathrm{PM}_{2.5}$ concentration experimental data, which consisted of samples collected from an air quality monitoring station located in the micro-region selected for this research. For all scenarios considered, concentration values predicted by the model were lower than experimental concentrations. The sensitivity analysis showed that the vehicular emissions factor influenced simulation results more than other input parameters. Thus more research in the area would be indispensable for obtaining specific emission factors for the region without discarding the possibility of establishing a vehicle inspection program through random sampling in Belo Horizonte.
\end{abstract}

Keywords: air quality, vehicle pollution, particulate matter, numerical simulation. 


\section{Introduction}

Environmental degradation caused by emission of atmospheric pollutants has significantly increased due to population and industrial expansion, mainly affecting large urban and industrial centers, places where air quality is inadequate, especially during droughts and in the winter.

Air pollution is defined as the discharge of any substance (particles or gases) into the atmosphere that alters the natural composition of the air, negatively affecting animal and vegetable species or provoking physical-chemical modification in minerals $[1,2]$.

Air pollution from both industrial and domestic sources has considerably decreased as a result of various governmental actions. At the same time, the increase in air pollution caused by vehicle emissions of particles and gases has increased significantly as the number of vehicles in circulation on roadways continually grows [3]. According to Sharma and Khare [4], the polluting capacity of automotive vehicles is the greatest of all human activities. Burning fuel in vehicle motors releases various gases and particles into the atmosphere, altering its original composition and causing it to become polluted. In large cities, in which there are large numbers of vehicles and constant traffic congestion, the vehicle fleet is responsible for around $72 \%$ of all toxic gases released into the atmosphere, causing a serious risk to human and animal life, and the environment [2].

One of the main atmospheric pollutants that originates from vehicle emissions is Particulate Matter (PM), classified as $\mathrm{PM}_{10}$ (diameter less than $10 \mu \mathrm{m}$ ) and $\mathrm{PM}_{2.5}$ (diameter less than $2.5 \mu \mathrm{m}$ ). The effects of PM on human health depend on greater or lesser to penetration into the respiratory system, which can vary from a simple allergic attack to lung cancer [1].

In this context, air quality monitoring becomes fundamental in defining atmospheric pollution control policies. Through implementation of a monitoring network, the evolution of pollution concentration in the atmosphere can be seen and the efficiency of emission control processes can be measured. The utilization of experimental techniques based mainly on monitoring networks allows air quality to be evaluated in real time for the positions that data is collected.

Pollution concentration investigation equipment is expensive and requires an infrastructure for continuous follow-up of operating conditions in order to guarantee the quality of information obtained. Numerical simulations are widely employed to evaluate the mechanisms by which pollution is dispersed into the atmosphere. They provide a theoretical estimation of air pollution levels, as well as special and temporal information about the evolution of these pollutants in the atmosphere [4]. Numerical simulation is also used to represent future scenarios, which allows control measures to be anticipated. The ability to accurately predict pollutant concentration levels becomes indispensable for identification and prevention of possible damage caused by new emissions sources or even by the modification of existing sources. Simulation also helps to identify critical positions where it is fundamental to install air quality monitors [5]. 
In order to expand knowledge of air quality in a specific region, experimental techniques are frequently used along with simulation tools. This combination of theoretical and experimental approaches is an important instrument in air quality evaluation.

Many studies of numerical models have been carried out with the intention of evaluating vehicle emissions' impact on air quality [4-6] Modified General Finite Line Source Model (M-GFLSM), Particulate Emissions factor Model (PART5), California Line Source - 3 (CALINE3), California Line Source - 4 (CALINE4), and California Line Source for Queuing \& Hot Spot Calculations (CAL3QHC) could be cited among the most utilized models. The performance of these models has been continuously evaluated by various authors, including those cited above, which helps to improve simulation results.

For this reason, the objective of this work is to apply the CAL3QHCR numerical model and evaluate its performance in a study of atmospheric dispersion of particulate matter $\left(\mathrm{PM}_{10}\right.$ and $\left.\mathrm{PM}_{2.5}\right)$ emitted by vehicular sources in a micro-region located in the center of the city of Belo Horizonte, Minas Gerais, Brazil. The results have been used to control air pollution, once it permits to identify critical points, allowing planners to use this approach as a tool for strategic traffic control in urban areas, intending to reach a better quality of life for inhabitants.

\section{Methodology}

\subsection{Definition of the study region}

The main criteria for selecting the study region were:

1. The micro-region chosen is in downtown Belo Horizonte (Figure 1), which is one of the critical regions in the municipality in relation to vehicle traffic according to information provided by the Belo Horizonte Transit and Transportation Company (BHTRANS);

2. The micro-region has a low level of influence from industrial pollution;

3. Existence of representative MET and ETS data;

4. Existence of an air quality monitoring station that considers data and concentration of fine $\left(\mathrm{PM}_{2.5}\right)$ and gross $\left(\mathrm{PM}_{10}\right)$ particulate matter.

\subsection{Model selection}

In the academic world, there is a consensus that CAL3QHCR is the best model for evaluating dispersion of pollutants generated by mobile sources [6-8). This model employs the Gaussian dispersal process to estimate concentrations of atmospheric pollutants (CO and PM) along roadways for moving vehicles and vehicles that are stopped at intersections with traffic signals. This model uses two types of links: free flow links, which represent intersections without signals, that is, with free flow; and queue links, which represents roadway segments with signals. 
The use of the CAL3QHCR dispersion model is based on the following premises:

1. The region to be analyzed has intense traffic with constant formation of traffic buildup;

2. In this region, vehicle flow varies considerably during the day and the week;

3. An adequate air quality study in this region requires application of information of periods longer than one hour.

\subsection{Scenarios}

The numerical simulations that were carried out for this study used 119 links as and were divided into four scenarios:

1. The first scenario corresponds to the study of $\mathrm{PM}_{10}$ pollutant dispersion, using Tier I;

2. The second scenario corresponds to the study of $\mathbf{P M}_{10}$ pollutant dispersion, using Tier II;

3. The third scenario corresponds to the study of $\mathrm{PM}_{2.5}$ pollutant dispersion, using Tier I;

4. The fourth scenario corresponds to the study of $\mathrm{PM}_{2.5}$ pollutant dispersion, using Tier II.

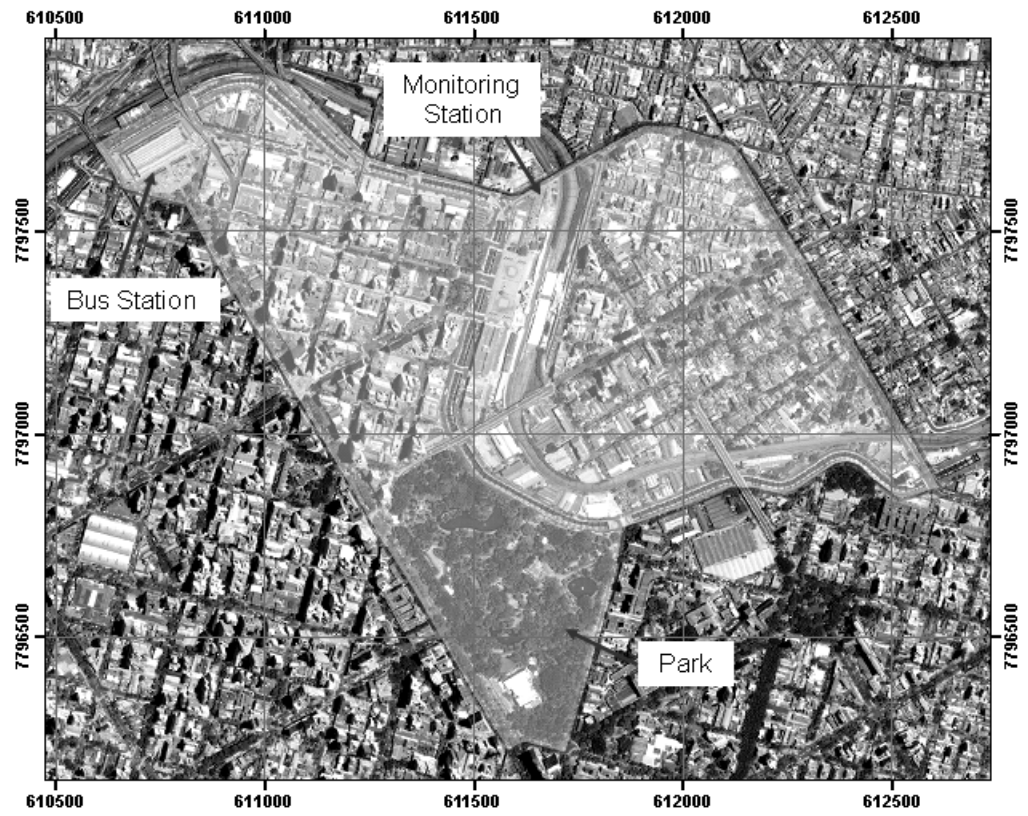

Figure 1: Outline that defines the micro-region in the study (Google MAPS, 2009, modified by the CDTN Geoprocessing Laboratory, 2009). 


\subsection{Obtaining data}

\subsubsection{Meteorological data}

The CAL3QHCR model is programmed to work with up to a complete year of meteorological data, and it is fundamental that the meteorological data acquired adequately represents the conditions in the study area. The meteorological station that provides the data for this work is located near the study area and provides information for all variables required by the model (wind direction and speed, environmental temperature, stability class, height of urban mixture, and height of rural mixture).

The meteorological data used for this study were provided by the Meteorological Station of the Center for Development of Nuclear Technology (CDTN), located approximately six kilometers from the air quality monitoring station located in the study region.

The MET data used in the simulations corresponded to the period from 16 February 2008 through 28 March 2008. The ETS data used varies for the type of pollutant $\left(\mathrm{PM}_{10}\right.$ or $\left.\mathrm{PM}_{2.5}\right)$ and the type of Tier (I or II). Other input data varies (links, surface roughness, etc.).

\subsubsection{Traffic volume and signalization data}

A lot of information is needed so that each stretch of selected roadway (link) can be adequately represented in the CAL3QHCR model. Traffic volume and signalization data for each roadway in the study micro-region were provided by BHTRANS. The relevant information referring to the study region had to be selected. The gaps that existed in the database were filled by using traffic knowledge of this region and adopting the principle of flow conservation.

\subsubsection{Emission factors}

Pollutant concentrations in the atmosphere are directly influenced by emission factors (EF) of these pollutants. The CAL3QHCR model uses different pollutant emission rates for the two types of links (free flow and queue links). Thus two types of vehicle emission factors are considered: moving vehicle emission factor, measured in $\mathrm{g} \mathrm{km}^{-1}$, and stopped vehicle emission factor, measured in $\mathrm{g} \mathrm{h}^{-1}$.

For moving vehicles, the emission factors recommended by the Environmental Sanitation Technology Company (CETESB) were used, since they are the most consistent with the Brazilian vehicle fleet, corresponding to $0.047 \mathrm{~g} \mathrm{~km}^{-1}$ for $\mathrm{PM}_{10}$ and $0.029 \mathrm{~g} \mathrm{~km}^{-1}$ for $\mathrm{PM}_{2.5}$ [2]. In Brazil, there are no official measurement records of emissions factors for stopped vehicles (According to information provided to the researchers by CETESB technicians.). For this reason data made available by the US EPA [9] were used, corresponding to $2.59 \mathrm{~g} \mathrm{~h}^{-1}$ for $\mathrm{PM}_{10}$ and $1.00 \mathrm{~g} \mathrm{~h}^{-1}$ for $\mathrm{PM}_{2.5}$.

\subsubsection{PM concentration measurement}

Determination of PM in the atmosphere was carried out using a Partisol 2000-D Dichotomous Air Sampler. This piece of equipment was installed in the air quality monitoring station located in the study region. The samples were taken in the period from 16 February through 28 March 2008. 


\subsection{Data processing}

Results obtained by means of numerical simulations were compared to the data shown in the station in Rui Barbosa Square. This comparison was carried out using a statistical tool so as to evaluate the performance of the model in determining average daily concentration of each of the pollutants considered.

There are various statistical parameters to compare predicted values $\left(\mathrm{C}_{\mathrm{p}}\right)$ and observed values $\left(\mathrm{C}_{\mathrm{o}}\right)$. These parameters serve to evaluate the degree that the model is under- or over-estimating observed values. The EPA recommends using the Fractional Bias (FB) parameter to make this type of comparison [10]:

$$
F B=\frac{\left(\bar{C}_{p}-\bar{C}_{o}\right)}{0,5 \cdot\left(\bar{C}_{p}+\bar{C}_{o}\right)},-2<F B<+2
$$

where $\overline{\mathrm{C}}_{\mathrm{p}}$ is the average of all of the predicted concentrations and $\overline{\mathrm{C}}_{\mathrm{o}}$ is the average of all of the observed concentrations.

Fractional Bias is a limiting, symmetric and adimensional factor between the values of -2 and +2 . FB values equal to -2 indicate that the model is underestimating the maximum observed values and FB values equal to +2 indicate that the model is overestimating the maximum values observed. $\mathrm{FB}= \pm 0.67$ means the concentration predicted is double or half of the observed concentration [11].

\section{Results and discussion}

\subsection{Concentration curves}

An analysis of the curves showed in Figure 2 points out that the concentrations of $\mathrm{PM}_{10}$ and $\mathrm{PM}_{2.5}$ predicted by the numerical simulation were less than the concentrations of $\mathrm{PM}_{10}$ and $\mathrm{PM}_{2.5}$ observed experimentally.

It's important to point out that the emissions factors used in the simulations refer only to the emissions released from the vehicle exhaust system. However, it is known that various sources that release PM into the atmosphere such as resuspension of dust and vehicle tire and brake wear contribute to observed concentrations. In this case, the use of receiver models allows the contribution percentage of each of the atmospheric pollution sources to be calculated and thus corrects the results of measured concentrations. Application of the receiver model [12] to PM collected in samples can reveal what percentage of PM is specifically caused by vehicle emissions. This method allows the difference between predicted and observed concentrations to be reduced.

Studies carried out in the city of Guwahati, India, for the purpose of evaluating the performance of different models of vehicular dispersion (CALINE3, M-GFLSM, and CAL3QHC) indicated that the CAL3QHC model generated the best results in predicting concentrations of $\mathrm{PM}_{10}$ and $\mathrm{PM}_{2.5}$ in the 
areas around roadways. The scenario considered consisted of a single intersection made up of two roadways which were divided into six links [8].

The comparison between the predicted and observed concentration curves was very similar. Fractional bias statistical factors obtained confirm the similarity between concentrations predicted by the model and those observed experimentally:

- $\mathrm{FB}=-0.1$ for $\mathrm{PM}_{10}$

- $\mathrm{FB}=-0.3$ for $\mathrm{PM}_{2.5}$

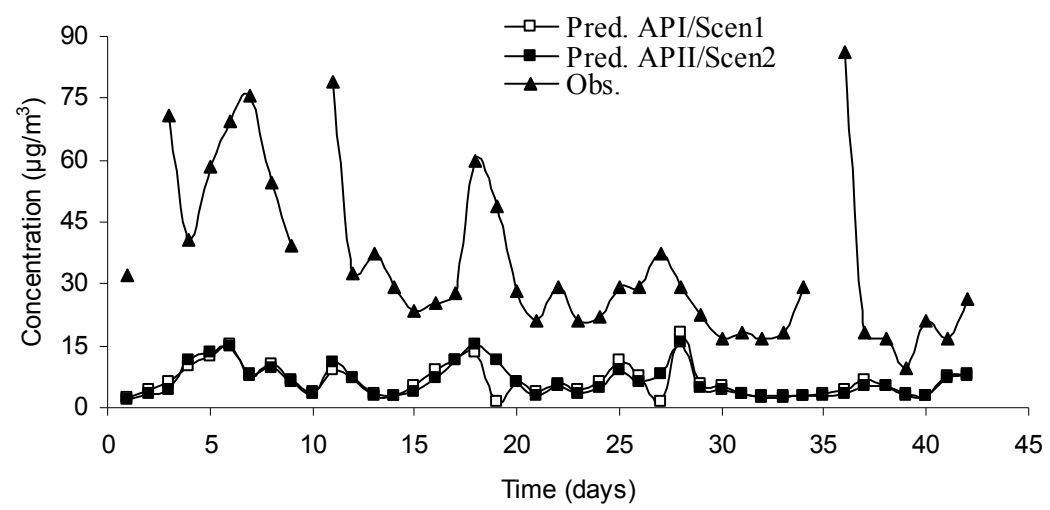

(a)

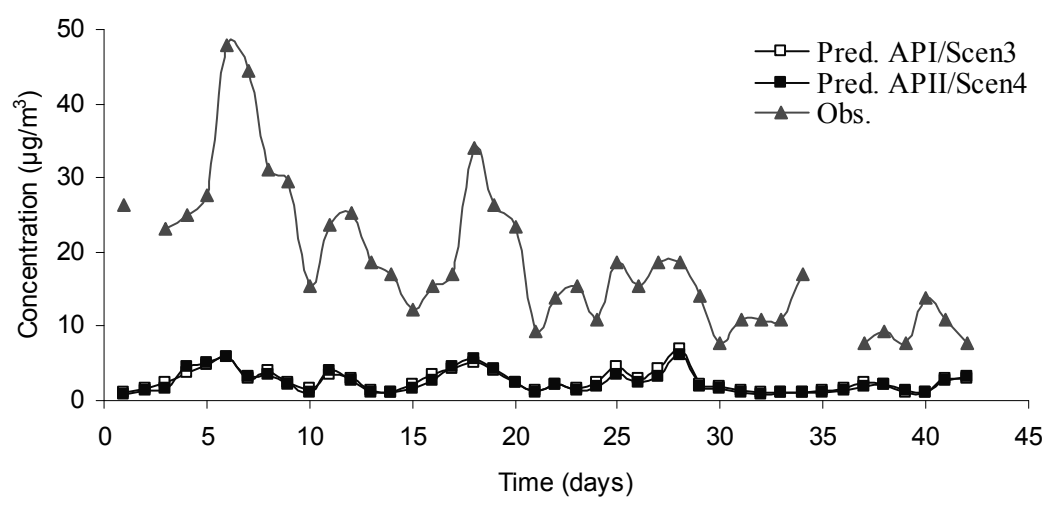

(b)

Figure 2: (a) Predicted and observed $\mathrm{PM}_{10}$ concentration curves for Scenario 1 and 2; (b) predicted and observed $\mathrm{PM}_{2.5}$ concentration curves for Scenario 3 and 4. 
The statistical analysis used in the Fractional Bias (FB) factor provides these results:

Scenario 1: $\mathrm{FB}=-1.38$;

Scenario 2: $\mathrm{FB}=-1.38$;

Scenario $3: \mathrm{FB}=-1.51$;

Scenario $4: \mathrm{FB}=-1.74$.

Considering that predicted pollutant concentrations were directly proportional to vehicle emissions factor, a possible explanation for this result would be use of emission factors that don't correspond to real values. In Brazil there is a lack of research in the area of vehicle emissions. The only registered source of this information is CETESB, which uses emission factors which aren't consistent with the reality of the fleet in Belo Horizonte because they are extracted from North American literature and because only new vehicles are considered.

However, the characteristics of the intersection studied in India are significantly different from the micro-region studied in Belo Horizonte - flat topography, slight influence of urban architecture in the dispersal process (canyons) and a low number of diesel vehicles when compared to the local fleet. Though they had satisfactory results, Gokhale and Raokhande [8] also attributed the small differences between $\mathrm{C}_{\mathrm{p}}$ and $\mathrm{C}_{\mathrm{o}}$ to emissions factors: that is, consistence with the local fleet. In addition, they emphasized the contribution of resuspension of particles in the results of sample concentrations.

Another observation to be discussed for the differences between $C_{p}$ and $C_{o}$ is that the model doesn't take into consideration the existence of so-called canyons, which are physical barriers that exist along links due to urban architecture (buildings, houses, trees, etc.). Because it doesn't consider complex topography, CAL3QHCR doesn't take into consideration the dispersion processes caused by canyons, which form wind tunnels and alter the way pollution is transported in the atmosphere. Studies using CAL3QHC $[6,13]$ also indicate that this model has limitations when used in urban areas, such as is the case of Belo Horizonte, since it doesn't take the existence of canyons or complex topographies into consideration.

Observing the concentrations curves in Figure 2, it can be seen that the predicted concentration results in Tiers I and II are similar. The difference between these two Tiers refers to traffic and signalization data. This result wasn't expected, since Tier II used the most detailed traffic volume and signalization data, which was closest to real traffic conditions.

A sensitivity analysis for these parameters revealed that the predicted pollutant concentrations weren't influenced by traffic volume. However, increase of red light duration contributes to increase in predicted concentrations, since the intensity of traffic buildup increases concomitantly. Thus the resemblance between the two Tiers indicates that the algorithm used by the CAL3QHCR model to estimate traffic buildup on roadways could be underestimating the reality of Brazilian traffic, or even that of developed countries. One could say that the existence of a more precarious infrastructure with a more advanced fleet age and a larger number of accidents contribute to the occurrence of more 
frequent and intense traffic buildup in developing countries when compared to developed countries.

\subsection{Iso-concentration lines}

The $\mathrm{PM}_{10}$ iso-concentration lines are shown in Figure 3. For concentrations between 0 and $50 \mu \mathrm{g} \mathrm{m}^{-3}$, air quality is considered GOOD; between 50 and 150 $\mu \mathrm{g} \mathrm{m}^{-3}$, NORMAL; between 150 and $250 \mu \mathrm{g} \mathrm{m}^{-3}$, INADEQUATE; between 250 and $420 \mu \mathrm{g} \mathrm{m}^{-3}$, BAD; and for concentrations $>420 \mu \mathrm{g} \mathrm{m}^{-3}$, TERRIBLE.

The absence of $\mathrm{PM}_{2.5}$ air quality standards in Brazil makes the existence of air quality indexes (IQAr) impossible for this pollutant. Therefore, air quality indexes adopted by the US EPA [14] were adopted. $\mathrm{PM}_{2.5}$ iso-concentration lines
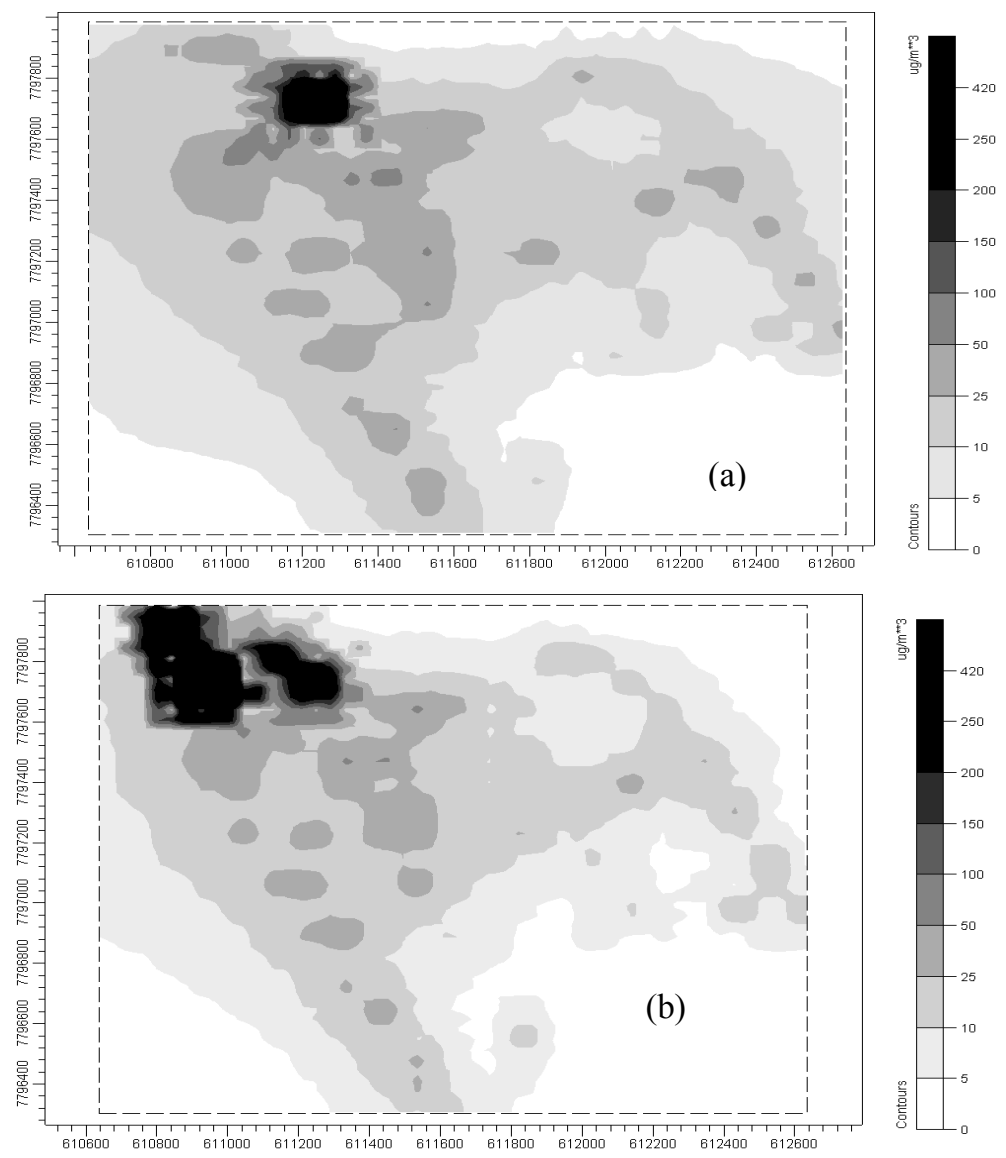

Figure 3: (a) $\mathrm{PM}_{10}$ iso-concentration lines for the maximum in 24 hours for Scenario 1. (b) $\mathrm{PM}_{10}$ iso-concentration lines for the maximum in 24 hours for Scenario 2. 
are shown on Figure 4. For concentrations between 0 and $15 \mu \mathrm{g} \mathrm{m}^{-3}$, air quality is considered Good; between 15 and $65 \mu \mathrm{g} \mathrm{m}^{-3}$, Normal; between 65 and $150 \mu \mathrm{g}$ $\mathrm{m}^{-3}$, Inadequate; between 150 and $250 \mu \mathrm{g} \mathrm{m}^{-3}, \mathrm{Bad}$; and for concentrations $>250$ $\mu \mathrm{g} \mathrm{m}^{-3}$, Terrible. For all four of the scenarios presented, the iso-concentration lines indicate that air quality is good in the majority of the micro-region. Nevertheless, there are areas where air quality varies from normal to terrible.

Places where air quality varies from normal to terrible correspond to a region of valleys with lower topography than the neighboring areas. These depressions, which make dispersion more difficult, increase pollutant residence time in these areas. This dispersion difficulty leads to an increase in pollutant concentration levels. Channelization of pollutant flow from the upwind to the downwind region could be verified in this valley, insofar as the predominant wind direction for the study period was from east to west.

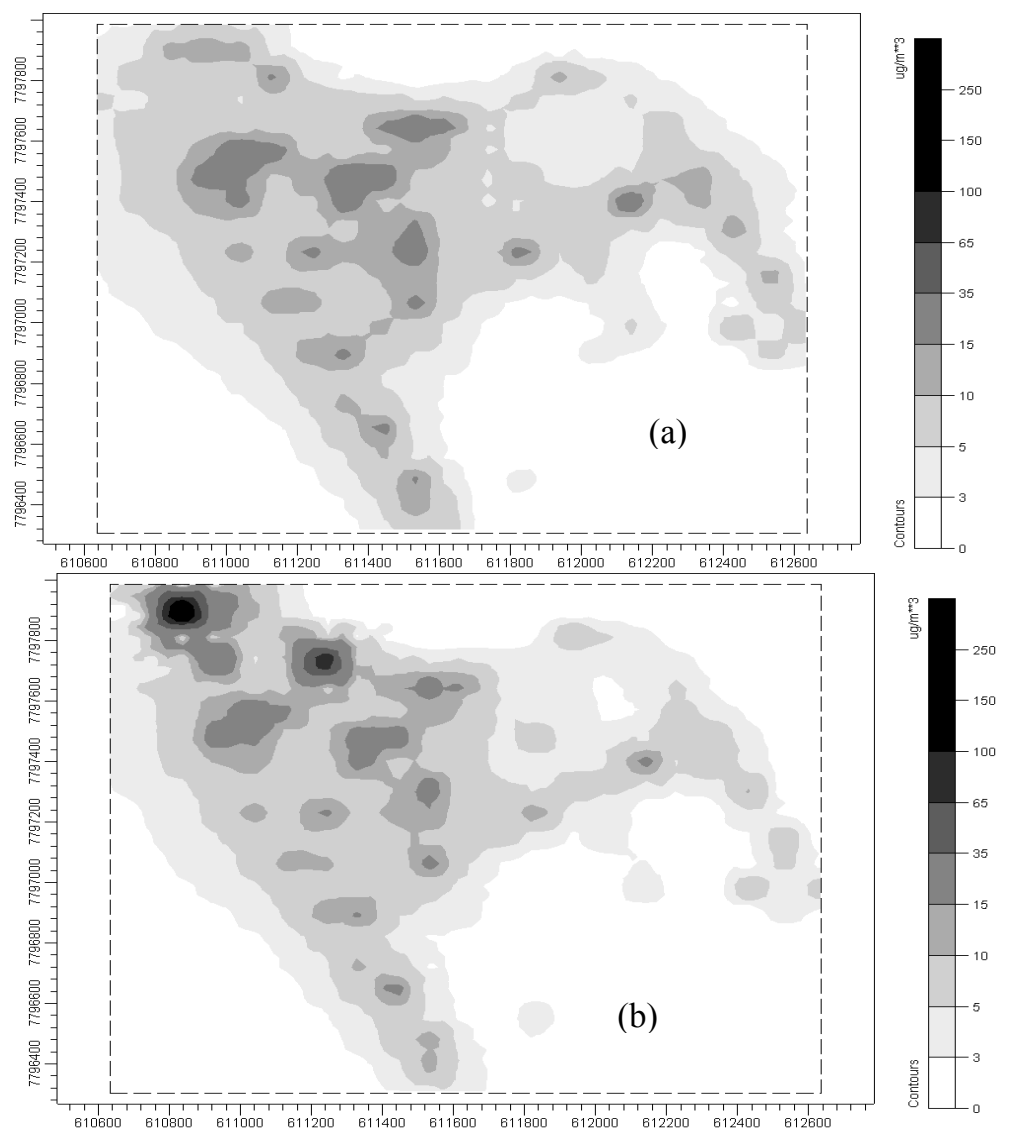

Figure 4: (a) $\mathrm{PM}_{2.5}$ iso-concentration lines for maximum in 24 hours for Scenario 3. (b) $\mathrm{PM}_{2.5}$ iso-concentration lines for the maximum in 24 hours for Scenario 4. 
Particularly in places that have larger concentrations of pollutants, vehicle traffic is intense, especially diesel vehicle (buses) traffic, which is considered the main releaser of PM into the atmosphere.

As can be seen, the iso-concentration lines are coherent with the topographical data (altitude of links), meteorological data (wind), traffic volume and signalization data. However, the concentration scale is probably inadequate since the emission factors in the algorithm used by the model to simulate traffic buildup on roadways could be underestimating the reality of the region's traffic.

\section{Conclusions}

The study carried out in this work revealed that concentrations of $\mathrm{PM}_{2.5}$ and $\mathrm{PM}_{10}$ predicted in the simulations were less than concentrations that were observed experimentally. One could say that the poor performance of the model was mainly a result of emission factors that weren't consistent with real values.

The sensitivity analysis carried out for CAL3QHCR demonstrated that emission factor is the parameter that has the greatest influence on predicted concentrations, which are directly proportional to vehicle emission factor. One measure that could contribute to obtaining emission factors for the region would be carrying out more research on this theme in Brazil, without discarding the possibility of implementing a vehicle inspection program using random sampling in the city of Belo Horizonte.

The emission factors used in the simulations refer only to emission released from vehicle exhaust; however, resuspension of dust, tire and brake wear contribute to emissions of PM into the atmosphere. Applying the receiver model to PM samples would be an important tool, since it decreases the difference between predicted and observed concentrations, since only the PM coming from vehicle exhaust would be considered for the PM sampled.

There is little difference in concentration results calculated by CAL3QHCR using Tiers I and II. This similarity between the two Tiers indicates that the algorithm used by CAL3QHCR to calculate traffic buildup on roadways could be underestimating the reality of traffic in developing countries. However, the isolines of Tiers I and II reveal the decay of air quality for Tier II. This result is due to the increase in red light duration in this Tier, which causes more traffic buildup. Thus, even though the results of Tier I are similar to Tier II, and the use of the latter is more complex, simulations using Tier II are important to reveal critical points where traffic buildup occurs and consequently contributes to worsening air quality.

Application of CAL3QHCR in large areas with numerous roadways is limited by the existence of traffic information. Studies involving large metropolitan areas must consider a large number of links. This situation demands the development of an extensive database which is difficult to format. Therefore the creation of a traffic volume database by BHTRANS is fundamental not just for organization of the city's traffic but also for air quality control studies.

Although the results of this study indicated that the evaluation of air pollution due to vehicular emissions and its effects to human health in developing 
countries still need a lot of research, they can be a start for the implementation of important strategies to improve air quality in Brazil, as an example: adoption of more effective regulation, introduction of cleaner vehicles, better land use planning, stimulation of public transportation, among others.

\section{References}

[1] Godish T. Air Quality. 3.ed. New York: Lewis Publishers, 1997. 448p.

[2] CETESB Relatório de Qualidade do Ar no Estado de São Paulo 2007. São Paulo: Companhia de Tecnologia de Saneamento Ambiental (CETESB) 2008. 298p. Relatório.

[3] Nagendra S M S, Khare M. Line source emission modeling-review. Atmospheric Environment, v. 36, nº.13, p. 2083-98, 2002.

[4] Sharma P, Khare M. Modeling of vehicular exhausts: a review. Transportation Research Part D: Transport and Environment, India, v. 6, $\mathrm{n}^{\mathrm{o}} .3$, p. 179-198, May 2001.

[5] Gokhale S, Khare M. A review of deterministic, stochastic and hybrid vehicular exhaust emission models. International Journal of Transport Management 2004; 2(2):59-74.

[6] Mishra V K, Padmanabhamutry B. Performance evaluation of CALINE3, CAL3QHC and PART5 in predicting lead concentration in the atmosphere over Delhi. Atmospheric Environment, v. 37, p. 3077-3089, 2003.

[7] Yura E A. et al. Using CALINE dispersion to assess vehicular PM 2.5 emissions. Atmospheric Environment, v. 41, p. 8747-8757, 2007

[8] Gokhale S, Raokhande N. Performance evaluation of air quality models for predicting $M P_{10}$ and $M P_{2.5}$ concentrations at urban traffic intersection during winter period. Science of the Total Environment, v. 394, p. 9- 24, Jan. 2008.

[9] US EPA. A Report on emission Factors, US Environmental Protection Agency (EPA), 1998.

[10] US EPA. Protocol for Determining the Best Performing Model. EPA Publication $\mathrm{n}^{\circ}$. EPA-454/R-92-025 Environmental Protection Agency, Pacific Northwest, December, 1992. US Environmental Protection Agency, 1992.

[11] Cox W M, Tikvart J A. A Statistical Procedure for Determining the Best Performing Air Quality Simulation Model. Atmospheric Environment, v. 24A, n. 9, p. 2387-2395, 1990.

[12] Queiroz Paula Guimarães Moura. Estudos da Poluição do Ar do Município de Sete Lagoas, MG Utilizando Técnicas Nucleares. 2006. Dissertação (Mestrado em Ciência e Tecnologia das Radiações, Minerais e Materiais) Centro de Desenvolvimento da Tecnologia Nuclear, Belo Horizonte, 2006.

[13] Zhou H, Sperling D. Traffic emission pollution sampling and analysis on urban streets with high rising buildings. Transportation Research. Part D, Transport and Environment, v. 6, p. 269-81, 2001.

[14] US EPA. Federal Register, Part III, v. 64, nº 149. Rules and Regulations: Air Quality Index Reporting; Final Rule. Agosto, 1999. US Environmental Protection Agency, 1999. 